\title{
A virtude como parte do ethos da balbúrdia universitária
}

\author{
Nathalia Melati
}

\section{Internet: acesso e personalização}

T á não muito tempo, a internet foi tida como marco da pluralidade e $\mathrm{H}$ conexão da humanidade. Santaella ${ }^{1}$ relembra como eufórico o momento em que o computador se tornou uma mídia comunicacional interativa e planetária. A internet tornou-se uma promessa que "iria democratizar o planeta, conectando-nos a informações melhores e nos dando a capacidade de interferir sobre elas ${ }^{2 "}$. De fato, representa uma revolução na comunicação humana, especialmente se nos focarmos nas redes sociais, que sempre foram usadas para atrair novos usuários para a web. Essas redes, ou pelo menos as mais relevantes, são usadas para estabelecer laços entre famílias, amigos ou simplesmente conhecidos que compartilham interesses similares.

No Orkut, os usuários dividiam-se em comunidades com nomes que representavam opiniões compartilhadas pelos membros, como Eu Odeio Acordar Cedo ou Não fui eu, foi meu eu-lírico. No Facebook, é possível seguir páginas e perfis que postam inúmeros textos com opiniões validadas pelo

Santaella, 2018.

2 Pariser, 2012, p. 9. 
número de curtidas, comentários e compartilhamentos. Já o Twitter apresenta tópicos que mostram a popularidade dos assuntos comentados. Com isso, os usuários são incitados a compartilhar pequenos textos com hashtags, ou palavras-chave, sobre o tema do momento. Até mesmo o WhatsApp, aplicativo de troca de mensagens em tempo real, possibilita que o usuário participe de grupos que replicam opiniões com as quais concordamos ou não.

A frequência de uso das redes sociais, visível pelo uso constante dos smartphones por todos, criou na internet um espaço em que "há sempre um alguém para mostrar um texto e um auditório à espreita, ávido por participar de uma polêmica, pois tem consciência de que todo discurso ou já é uma resposta ou aguarda uma resposta ${ }^{3 "}$. Essa interação, que se dá a todo o instante, envolve não só a comunicação entre pessoas conhecidas, como também com agentes culturais, políticos e religiosos. É na internet que acontece parte dos debates sobre a organização da sociedade de maneira geral.

Apesar de parecer universal, nem toda a população possui internet. Percebe-se, no entanto, uma rápida evolução nessa área. Em 2016, 67,9\% da população brasileira residia em domicílios com acesso à internet. No ano seguinte, essa proporção passou para $74,8 \%$. Em relação aos mais pobres, o percentual da população residindo em domicílios com acesso à internet passou de 47,8\%, em 2016, para 58,3\%, em $2017^{4}$. Em 18 de julho de 2018, o WhatsApp, por exemplo, atingiu 127 milhões de usuários no país.

Ainda assim, devemos considerar que há discursos, oradores e auditórios que não estão em rede. Por isso, os textos on-line retratam o discurso de uma parte da sociedade e devem ser assim compreendidos. Outro ponto a ser considerado é a personalização da internet, utilizada como base produtos como Google, Facebook e Twitter. Cada uma dessas redes personaliza o conteúdo apresentado ao usuário, ou seja, há uma filtragem entre as publicações que de fato o público obtém acesso. Como explica o autor,

o código básico no seio da nova internet é bastante simples. A nova geração de filtros on-line examina aquilo de que aparentemente gostamos - as coisas que fazemos, ou as coisas das quais as pessoas parecidas conosco gostam - e tenta fazer extrapolações. São mecanismos de previsão que criam e refinam constantemente uma teoria sobre quem somos e sobre o que vamos fazer ou desejar a seguir. Juntos, esses mecanismos criam um universo de informações exclusivo para cada um de nós - o que passei a chamar de

Ferreira, 2019, p. 78.

4 IBGE, 2018. 
bolhas dos filtros - que altera fundamentalmente o modo como nos deparamos com ideias e informações 5 .

Essas bolhas operam como câmaras de eco, ou seja, um "ecossistema individual e coletivo de informação viciadas na repetição de crenças inamovíveis". Os filtros são formados a partir de cada passo dado nos ambientes virtuais, como o histórico de busca, as compras realizadas on-line, os anúncios em que decidimos clicar e, até mesmo, as escolhas feitas por outros perfis com quem interagimos mais frequentemente. É por focalizarem sempre o que clicamos que há um desequilíbrio na busca por informação.

Ou seja, a personalização torna possível a diminuição do contato com determinados assuntos. Se não interagimos com notícias sobre a fome no mundo, por exemplo, os algoritmos compreendem isso como falta de interesse sobre o assunto e diminuem a frequência de aparecimento do tema. As redes sociais permitem uma interação com um mundo sob medida, "se nunca mais quisermos ouvir falar de reality shows (...), não precisaremos mais ouvir falar - e, se só estivermos interessados em saber de cada movimento de Reese Witherspoon, teremos essa possibilidade”".

Para Pariser, as nossas telas passaram a nos mostrar um espelho que reflete aquilo que nos interessa com base nas nossas preferências. Cada clique que realizamos é observado pelo algoritmo que busca nos oferecer opções cada vez mais compatíveis. Esse movimento é visto como benéfico quando encontramos com mais rapidez um produto que estávamos procurando ou com a sugestão acertada de um filme, por exemplo. É possível, no entanto, que as redes sociais contribuam para nos cercar de discursos que reproduzem teses com as quais já concordamos.

\section{Identidade: nós e o outro}

Segundo Wardle e Derakhsham ${ }^{8}$, as redes que permitem qualquer tipo de interação social incentivam um posicionamento individualista na nossa própria rotina diária. Dessa forma, elas sempre nos instigam a compartilhar a

\footnotetext{
Pariser, 2012, p. 14.

Santaella, 2018, p. 9.

Pariser, 2012, p. 16, grifo do autor

Wardle; Derakhsham, 2017a.
} 
nossa própria identidade. Com base nas nossas preferências, as redes sociais podem extrapolar e buscar opções de conteúdo para oferecer em seguida. Se quem somos está, de alguma forma, espalhado pelas nossas redes, então os textos com os quais interagimos reforçam a imagem que queremos passar ao outro.

Para Meyer, as relações humanas derivam do jogo da identidade e da diferença, "a identidade dá conta das nossas simpatias, das nossas aproximações e de tudo o que, em geral, definiu o comunitário; a diferença, pelo contrário, demarca-se pela oposição e pela exclusão, pela distância e pelas relações de poder ou de estatuto"”. Se construímos a nossa identidade também nas redes sociais, então é nesse ambiente que fazemos uso dos discursos nos aproximando e nos afastando de textos que expressam opinião.

Sobre os textos que circulam em rede, Ferreira ${ }^{10}$ os divide em três tipos de discurso: autoritário, polêmico e fluido. O primeiro veicula um discurso autorizado institucionalmente, como sites governamentais, científicos, pedagógicos ou religiosos, e é responsável por assegurar os pilares institucionais. O último, discurso fluido, produz mensagens dos mais variados tipos, desde autoajuda até pensamentos filosóficos.

É o discurso polêmico, no entanto, que triunfa nas redes sociais. Os oradores desses textos buscam defender posições diversas sobre a mesma questão retórica. É esse jogo entre discursos contrários que cria a polêmica. De acordo com o autor, o gênero predominante nesse campo é o deliberativo porque "o discurso polêmico toma como valores o útil e o nocivo em busca do bem comum, delibera sobre um fato futuro, aconselha ou desaconselha ${ }^{11}$ ".

Acrescenta-se a esse discurso a visão de Meyer de que a retórica é capaz de anular as diferenças com o objetivo de criar a identidade. Isso acontece porque, apesar de existir um jogo discursivo de identidade e diferenças, o orador busca sempre reencontrar a sua identidade. Se adicionarmos a questão tecnológica, perceberemos que o próprio mecanismo das redes sociais nos oferece mais conteúdo com o qual simpatizamos. Reforçamos, então, a nossa identidade ao mesmo tempo em que nos distanciamos do diferente.

9 Meyer, 2018, p. 135.

10 Ferreira, 2019.

11 Id., 2019, p. 83. 
Para Meyer, duas lógicas operam na negociação entre as aproximações e os distanciamentos: a violência e a sedução, o vencer e o convencer. A lógica da sedução objetiva diminuir as distâncias e, por isso, opera como se elas não existissem ou fossem irrelevantes. Já a lógica da violência, ou do predador, exclui o terceiro, vencendo-o.

Por conta da velocidade da internet e da facilidade da disseminação de textos nas redes sociais, compreendemos que o compartilhamento de textos, bem como outras interações on-line, contribui para a busca e a reafirmação da própria identidade do usuário. Com isso, tornou-se tão importante construir uma identidade tanto on-line como presencialmente. De acordo com Amossy,

todo ato de tomar a palavra implica a construção de uma imagem de si. Para tanto, não é necessário que o locutor faça seu autorretrato, detalhe suas qualidades nem mesmo que fale explicitamente de si. Seu estilo, suas competências linguísticas e enciclopédicas, suas crenças implícitas são suficientes para construir uma representação de sua pessoa. Assim, deliberadamente ou não, o locutor efetua em seu discurso uma apresentação de $\mathrm{si}^{12}$.

A retórica nomeia essa construção da imagem de si como ethos. Cada texto publicado on-line veicula em si mesmo a imagem do orador daquele discurso. Essa imagem, por sua vez, colabora para a persuasão do auditório porque contribui para a criação da identidade do leitor. Compartilhar ou curtir um texto on-line, ou mesmo deixar um comentário, é uma forma de propagar uma imagem de si aos outros usuários.

A partir dessas interações é possível compreender o engajamento daquele discurso perante a sociedade. Uma vez que, de acordo com Ferreira, a argumentação busca uma mudança, ou seja, almeja modificar a opinião do auditório. O resultado disso é que: "um texto, então, se bem estruturado e legível para um auditório particular, pode disseminar um discurso instituinte, que se introjeta no discurso dominante e transforma-se em instituído e socialmente aceito ${ }^{13 "}$. A análise do ethos de um discurso on-line permite compreender, de certa forma, os elementos que compõem essa identidade compartilhada.

12 Amossy, 2018a, p. 9.

13 Ferreira, 2019, p. 77. 


\section{Ethos: a balbúrdia universitária}

Ao estudarmos um texto retoricamente, normalmente enfatiza-se uma das três perspectivas possíveis que a retórica apresenta a um texto. É possível analisar um texto com base na palavra em si ao enfatizar o logos. A maneira como esse texto move as paixões do auditório é examinado por meio da análise do pathos. O ethos, por fim, debruça-se sobre o caráter do orador visto que é essencial ao discurso que o auditório perceba esse orador como alguém digno de crédito. $\mathrm{O}$ estudo do orador, do auditório ou do discurso não possibilita, no entanto, uma cisão tão clara entre logos, pathos e ethos.

Para Aristóteles (384-322 a.C.), persuadir o auditório a partir do ethos "deve ser conseguido pelo que é dito pelo orador, e não pelo que as pessoas pensam acerca do seu caráter antes que ele inicie o discurso ${ }^{14}$ ". Eggs, ao retomar os estudos aristotélicos, defende que o orador deve demonstrar pelo discurso um caráter honesto, para que esse discurso seja disseminado pelo seu auditório. É por isso que é necessário ao orador inspirar confiança no auditório por meio das três provas retóricas. O autor propõe, então, que: "os oradores inspiram confiança, (a) se seus argumentos e conselhos são sábios, razoáveis e conscientes, (b) se são sinceros, honestos e equânimes e (c) se mostram solidariedade, obsequiedade e amabilidade para com seus ouvintes"15.

Dentre os elementos que contribuem para a construção do caráter do orador, destacamos a virtude. De acordo com Aristóteles, "a virtude é, segundo a opinião geral, a faculdade responsável pela aquisição e preservação das coisas boas ${ }^{16 "}$. Também os discursos polêmicos, que circulam nas redes sociais, buscam exaltar a virtuosidade do orador. Com isso, a identidade compartilhada pelo auditório será a de um homem que busca as partes da virtude: "a justiça, a coragem, a moderação, a magnificência, a magnanimidade (grande da alma) a generosidade, a brandura, a prudência e a sabedoria ${ }^{17 "}$.

Para colaborar com os estudos retóricos, este capítulo escolheu um texto a partir de uma análise realizada pela Aos Fatos. Essa plataforma define a checagem de fatos como um método jornalístico por meio do qual é possível conferir se a informação apurada foi obtida por meio de fontes confiáveis e avaliar se é verdadeira ou falsa, se é sustentável ou não. Uma

$14 \quad$ Aristóteles, 2011, p. 45.

15 Eggs, 2018, p. 37, grifo do autor.

16 Aristóteles, 2011, p. 81.

17 Ibid., p. 81. 
vez que a checagem jornalística foi prejudicada pelo dinamismo surgido na internet, torna-se agora uma segunda etapa da apuração após a publicação das reportagens mais relevantes ao contexto social.

O método empregado pela plataforma Aos Fatos consiste em sete etapas. A primeira é a seleção de uma informação pública a partir da sua relevância. Em seguida, com o objetivo de checar esse conteúdo, a plataforma consulta fonte original, fontes de origem confiável, fontes oficiais e fontes alternativas. Com esse levantamento em mãos, a informação é contextualizada e, posteriormente, classificada como: verdadeira, imprecisa, exagerada, contraditória, insustentável, distorcida ou falsa. Dessa forma, o texto analisado por este capítulo integra um episódio relevante para a informação pública e veicula, em algum espectro, uma fake news.

À época da circulação do texto, Abraham Weintraub, ministro da Educação do governo de Jair Bolsonaro (PSL), disse em entrevista para o jornal O Estado de S.Paulo que as universidades que fizerem balbúrdia em vez de melhorarem o desempenho acadêmico terão as verbas reduzidas. $\mathrm{O}$ ministro caracterizou balbúrdia como eventos políticos, manifestações partidárias ou festas inadequadas que ocorrem dentro das instalações universitárias. Em seguida, a UFBA (Universidade Federal da Bahia), a UFF (Universidade Federal Fluminense) e a UnB (Universidade de Brasília) tiveram 30\% das suas dotações orçamentárias anuais bloqueadas. Ainda de acordo com a publicação:

ao Estado, em sua primeira entrevista no cargo, Weintraub reforçou a diretriz e disse que a política para universidades tem de respeitar "os pagadores de impostos". "Quando vão na universidade federal fazer festa, arruaça, não ter aula ou fazer seminários absurdos que agregam nada à sociedade, é dinheiro suado que está sendo desperdiçado num país com 60 mil homicídios por ano e mil carências"18.

As despesas das universidades federais são divididas em obrigatórias e discricionárias. Entre as obrigatórias estão o salário dos servidores e as aposentadorias, que por lei são garantidas. Já as discricionárias, atingidas pelo bloqueio do Ministério da Educação (MEC), incluem despesas de custeio,

18 Agostini, 2019. 
ou seja, contas de água e energia, serviços de limpeza e bolsas acadêmicas; e investimento e capital, gastos ligados a obras das universidades ${ }^{19}$.

No mesmo dia em que a entrevista do ministro Abraham Weintraub foi publicada pelo Estadão, o jornal Folha de S.Paulo ${ }^{20}$ indicou que o bloqueio de $30 \%$ dos recursos seria realizado em todas as universidades federais. Após esse anúncio, entre os dias 1 e 2 de maio de 2019, o envio de imagens de estudantes nus cresceu cerca de $950 \%$ em 350 grupos abertos de WhatsApp. Esse levantamento foi realizado pela Aos Fatos a partir de uma ferramenta de monitoramento desenvolvida pela UFMG (Universidade Federal de Minas Gerais) ${ }^{21}$. As imagens compartilhadas criticavam as universidades e elogiavam o bloqueio orçamentário. O texto abaixo foi compartilhado ao menos 105 mil vezes e, por isso, chegado pela plataforma Aos Fatos ${ }^{22}$ :
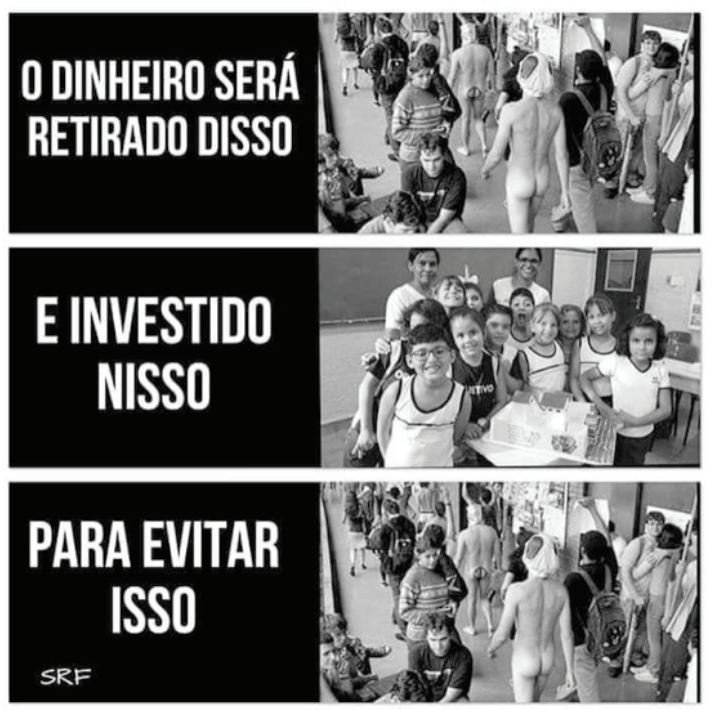

O texto, composto por foto e texto, é meme. Esse gênero digital, criado para circulação em redes sociais via internet, é formado "por imagens, figu-

\footnotetext{
19 Aos Fatos, 2019.

20 Cf. Saldaña, 2019.

21 Cf. Ribeiro, 2019a.

22 Id., 2019a.
} 
ras, fotografias, frases ou qualquer elemento que transmita uma mensagem irônica ou humorística ${ }^{23}$ ". De acordo com o texto, o dinheiro investido em universidades federais fomenta situações em que alunos caminham nus livremente entre outros estudantes. Esse dinheiro seria, por isso, retirado e investido em educação básica para evitar esse comportamento pelos futuros universitários. Este meme se pauta no compartilhamento de valores de um grupo que considera qualquer tipo de manifestação do nu como algo negativo. Como a concepção de que o nu é ofensivo faz parte do senso comum, a possibilidade de compartilhamento é ampliada.

Primeiramente, conforme checagem apresentada por Ribeiro, a primeira imagem registra um protesto realizado na UnB, em $2009^{24}$. O ato apoiava a estudante Geisy Arruda, hostilizada na Uniban (Universidade Bandeirante de São Paulo), em São Bernardo do Campo, por usar roupas consideradas muito curtas. Depois, apesar de a montagem sugerir, por conclusão lógica, um investimento na educação básica da rede pública, a foto escolhida para ilustrar esse setor é de alunos vestidos com uniforme do sistema de ensino Objetivo, pertencente à rede privada.

Com a ampliação do debate sobre a presença de notícias falsas on-line, é ainda necessário analisar o texto sob o ponto de vista da desordem informativa, apresentado por Wardle e Deraksham ${ }^{25}$. Podemos classificar a imagem circulada pelo WhatsApp como uma informação falsificada, ou seja, uma informação falsa criada deliberadamente com o objetivo de prejudicar um grupo social, delimitado como participantes da esfera da educação universitária federal. Nesse caso, a estratégia usada para gerar informação falsa compreende um contexto falso. Assim, apesar de a foto ser genuína, o meme não apresenta informação contextual adequada: falha em explicar que o nu representava um protesto e, portanto, a situação não faz parte do cotidiano universitário. Há ainda uma conexão falsa na imagem quando analisamos que a foto que representa a rede pública de educação básica retrata, é, na verdade, uma instituição privada.

No campo retórico, esse texto é um discurso polêmico que obteve a adesão do auditório, uma vez que foi compartilhado por, pelo menos, 105 mil usuários. É polêmico porque reforça a concepção de que o investimento em educação básica é preferível ao em educação superior. A educação básica é, assim, mais útil ao bem comum. Mais grave é pensar que o texto

23 Ribeiro; Freitas, 2018, p. 99.

24 Também confirma essa informação matéria publicada pela Agência Estado (2009).

25 Wardle; Deraksham, p. 2017b. 
opera como uma promessa de educação de qualidade apesar de não fazer parte de um discurso autorizado institucionalmente.

Sem a autoria real do autor do discurso, devemos classificá-lo como autor apócrifo, uma vez que "o criador primeiro e efetivo se esvanece e o texto fica à mercê dos interesses de um pseudoautor, incerto, colateral, sem vínculo com a referência primeira ${ }^{26 "}$. O texto, que parece ter como objetivo explicar os bloqueios envolvendo a educação superior, é uma fake news porque induz o leitor a uma concepção errada acerca da realidade. Mas, justamente por ter um autor apócrifo, o texto não representa um discurso autorizado institucionalmente.

Além disso, ao retomar Meyer ${ }^{27}$, compreendemos que a lógica utilizada por esse orador é a do predador, pois exclui o terceiro. A universidade, nesse contexto, não é parte da discussão sobre o uso de verbas públicas. Tal exclusão é feita com a desqualificação da identidade dos estudantes dessas instituições. Assim, os estudantes não apresentam as três qualidades que inspiram confiança no auditório: a phrónesis, a areté e a eúnoia. Por optarem por protestar nus, apesar de a prática não ser considerada instituída e socialmente aceita, os estudantes não inspiram a confiança do auditório.

Justamente por se apresentar na posição oposta, o orador desse texto inspira, por sua vez, confiança. O seu conselho - ampliar o investimento público no ensino básico do país - é prudente, virtuoso e benevolente ${ }^{28}$. Ao interagir com esse texto, o leitor reafirma para si as qualidades apresentadas pelo ethos do orador. Assim, apesar de optar pela exclusão do ensino superior, o discurso também reafirma que tanto orador quanto auditório estão "juntos, mas ao mesmo tempo existe outro que constitui o lado de fora e que é verdadeiramente o outro ${ }^{29}$ ". Com isso, o texto reforça a identidade do leitor e do autor, que compartilham a mesma virtude, e ainda reforça a diferença com o verdadeiro outro: o terceiro.

26 Ferreira, 2019, p. 86.

27 Meyer, 2018.

28 Phrónesis, areté e eúnoia, cf. Eggs, 2018.

29 Meyer, 2018, p. 136. 


\section{Considerações finais}

Podemos crer que quem compartilhou o texto analisado compreende o ethos estabelecido como parte de sua identidade. Observar o orador, nesse caso, é também tentar compreender o que move o auditório e impulsiona a sua interação digital. Conforme delimitado por Eggs, o orador do meme apresenta-se como honesto e sincero. É honesto na escolha da educação básica em razão do ensino superior ao mesmo tempo em que é sincero em relação à consequência de sua ação: "o dinheiro será retirado". Com isso, também segundo o autor, o que é verdadeiro e justo se impõe. $\mathrm{O}$ auditório acredita que o dinheiro será retirado e reinvestido (ao invés de bloqueado) em uma área de uma educação mais justa.

É curioso que uma fake news se apoie justamente no caráter do orador para construir a sua argumentação. Principalmente porque esse caráter é marcado pela honestidade e sinceridade, características essas questionáveis, uma vez que o discurso falha na contextualização das imagens e faz uma conexão errada entre a educação básica pública e privada.

Apesar de a busca pelo bem da comunidade aparecer em primeiro plano, há também uma imposição de que as universidades não fazem mais parte da identidade de um auditório online. Desvaloriza-se, assim, parte de um discurso institucional científico. É também necessário explorar, a partir de pesquisas acadêmicas, de que forma as novas tecnologias da internet influenciam a comunicação digital e como as fake news contribuem para esse cenário. 


\section{Referências}

AGÊNCIA ESTADO. Alunos da UnB ficam pelados em defesa de Geisy. 2009. Disponível em: < http://entretenimento.r7.com/jovem/noticias/alunos-da-unbficam-pelados-em-defesa-de-geisy-20091112.html> Acesso em: 25 de mai. 2019.

AGOSTINI, R. MEC cortará verba de universidade por 'balbúrdia' e já enquadra UnB, UFF e UFBA. 2019.

Disponível em: < https://educacao.estadao.com.br/noticias/geral,mec-cortara-verba-de-universidade-por-balburdia-e-ja-mira-unb-uff-e-ufba,70002809579> Acesso em: 25 de mai. 2019.

AMOSSY, R. Da noção retórica de ethos à análise do discurso. In: AMOSSY, R (org.). Imagens de si no discurso: a construção do ethos. $2^{\mathrm{a}}$ edição. $3^{\mathrm{a}}$ reimpressão. São Paulo: Contexto, 2018.

R. O ethos na intersecção das disciplinas: retórica, pragmática, sociologia dos campos. In: AMOSSY, R (org.). Imagens de si no discurso: a construção do ethos. $2^{\circ}$ edição. $3^{\mathrm{a}}$ reimpressão. São Paulo: Contexto, 2018.

AOS FATOS. O que é checagem de fatos - ou fact-checking? s/d. Disponível em: <https://aosfatos.org/checagem-de-fatos-ou-fact-checking/> Acesso em: 25 de mai. 2019.

Nosso Método s/d. Disponível em: < https://aosfatos.org/nosso-m\%C3\%A9todo/> Acesso em: 25 de mai. 2019.

Desenhamos fatos sobre o orçamento das universidades federais. 2019a. Disponível em: <https://aosfatos.org/noticias/desenhamos-fatos-sobre-o-orcamento-das-universidades-federais/> Acesso em: 25 de mai. 2019.

ARISTÓTELES. Retórica. Tradução, textos adicionais e notas Edson Bini. São Paulo: EDIPRO, 2011.

EGGS, E. Ethos aristotélico, convicção e pragmática moderna. In: AMOSSY, R (org.). Imagens de si no discurso: a construção do ethos. $2^{\circ}$ edição. $3^{\mathrm{a}}$ reimpressão. São Paulo: Contexto, 2018.

FERREIRA, L. A. A retórica dos vigilantes: autorias online. EID\&A-Revista Eletrônica de Estudos Integrados em Discurso e Argumentação, Ilhéus, n. 18, p. 74-89, abr.2019. DOI dx.doi.org/10.17648/eidea-18-2314.

IBGE, Coordenação de População e Indicadores Sociais. Síntese de indicadores sociais: uma análise das condições de vida da população brasileira: 2018. Rio de Janeiro: IBGE, 2018.

MEYER, M. Questões de retórica: linguagem, razão, sedução. Lisboa/Portugal: EDIÇÕES 70, 2018.

PARISER, E. O filtro invisível: o que a internet está escondendo de você. Rio de Janeiro: Zahar, 2012. 
PERELMAN, C.; OLBRECHTS-TYTECA, L. Tratado de argumentação: a nova retórica. $3^{\mathrm{a}}$ edição. São Paulo: Editora WMF Martins Fontes, 2014.

RIBEIRO, A. Após cortes no MEC, envio de imagens de estudantes nus cresce $950 \%$ em grupos de WhatsApp em 24 horas. 2019. Disponível em: < https:// aosfatos.org/noticias/apos-cortes-no-mec-envio-de-imagens-de-estudantes-nuscresce-950-em-grupos-de-whatsapp-em-24-horas/> Acesso em: 25 de mai. 2019.

RIBEIRO, J.; FREITAS, M. Desvendando os memes: uma proposta para o ensino da leitura e escrita. In: FERREIRA, L. A. (org.). Retórica, escrita e autoria na escola. São Paulo: Blucher, 2018.

SALDAÑA, P. MEC estende corte de $\mathbf{3 0} \%$ de verbas a todas universidades federais. 2019. Disponível em: < https://www1.folha.uol.com.br/educacao/2019/04/ mec-estende-corte-de-30-de-verbas-a-todas-universidades-federais.shtml $>$ Acesso em: 25 de mai. 2019.

SANTAELLA, L. A pós-verdade é verdadeira ou falsa? Barueri, SP: Estação das Letras e Cores, 2018.

WARDLE, C.; DERAKHSHAN, H. How did the news go "fake"? When the media went social. 2017b. Disponível em: <https://www.theguardian.com/ commentisfree/2017/nov/10/fake-news-social-media-current-affairs-approval $>$ Acesso em: 25 de mai. 2019. , H. Information disorder: toward an interdisciplinary framework for research and policy making. Council of Europe, Out., 2017b. 
